\title{
A Feasible Operative Treatment Strategy for Trauma Patient with Difficulties in Closing the Abdomen during Open Abdomen Management (OAM) Following Damage Control Surgery-Secondary Publication $^{\text {is }}$
}

\author{
Futoshi Nagashima ${ }^{\mathrm{a}, *}$, Satoshi Inoue ${ }^{\mathrm{b}}$ \\ a Department of Emergency Medicine, Advanced Emergency Medicine and Critical Care Center, Saga University Hospital, Saga, Japan \\ ${ }^{b}$ Division of Trauma Surgery and Surgical Critical Care, Saga University Hopital, Saga, Japan
}

\section{Article history:}

Received: July 21, 2020

Accepted: October 16, 2020

* Corresponding Author:

Futoshi Nagashima

Department of Emergency Medicine, Advanced Emergency Medicine and

Critical Care Center, Saga University

Hospital, Nabeshima 5-1-1, Saga city, Saga

Prefecture, 849-8501 Japan

ORCID

Futoshi Nagashima

https://orcid.org/0000-0003-2787-7366

Satoshi Inoue

https://orcid.org/0000-0001-9282-0644

\begin{abstract}
The vacuum packing closure (VPC) is often performed as temporal abdominal closure after damage control surgery (DCS). We occasionally encounter severe trauma patients whose abdomens were unable to be closed after DCS. The bilateral anterior rectus abdominis sheath flap turnover method and component separation (CS) method are one of the options to close the abdomen. However, it can be challenging to close the abdomen in some patients with very severe trauma or obesity by these methods. The open abdomen management (OAM) with a planned ventral hernia can be performed in those patients. The patients with long term OAM occasionally develop persistent enteroatmospheric fistula (EAF). The VPC using absorbable mesh is useful to reduce the likelihood of EAF. The posterior component separation with transversus abdominis release is a useful method for delayed abdominal wall reconstruction following planned VH if bilateral anterior rectus abdominis sheath flap turnover method and CS method are unable to be performed.
\end{abstract}

Keywords: abdominal wound closure techniques, fistula, surgery, trauma

\section{Introduction}

Damage control surgery (DCS) is standard treatment strategy for severe trauma cases accompanied with deadly triad (bloody vicious cycles) improving survival rate. Appropriate implement of DCS has decreased the mortality, however, serious complications such as ventral hernia $(\mathrm{VH})$, enteroatmospheric fistula (EAF), the cases which is unable to close the abdominal wall have been increased in proportion to increase of abbreviated surgery and open abdomen management (OAM) [1]. Damage control resuscitation (DCR) has reduced the number of cases requiring DCS and mortality, and improved the rate of fascial closure, but there are still some cases which unable to close the abdominal wall closure despite appropriate DCR [2].

In this article, we report 1 ) temporary abdominal closure method following DCS, 2) key points of OAM for definitive abdominal closure following DCS, 3)various definitive abdominal closure methods for difficult cases of abdominal closure following DCS, 4) surgical treatment guideline in our trauma center for definitive abdominal closure in the OAM following DCS. 


\section{Temporary Abdominal Closure Method Following DCS}

DCS is an abbreviated surgical procedure mainly focusing on controlling bleeding and contamination, requiring quick conversion to intensive care to improve deteriorated physiologic state. For this purpose, a temporary abdominal closure method is adopted upon which abdominal closure method in consideration of prevention of abdominal compartment syndrome (ACS) [3], monitoring of the amount of bleeding and management of drainage. etc.

Historically, there have been so many kinds of temporary abdominal closure methods. As a simplified method, skin suture method and towel clip method can be considered. However, they have the very poor preventive effect of ACS. Currently, common abdominal closure methods include vacuum packing closure (VAC) [4] represented by Barker method and silo closure method and etc. Common point of these methods is to be able to prevent the occurrence of ACS. VPC is a method using so-called drape gauze which affixed one side of it by loban ${ }^{\mathrm{TM}}$ drape and made many slits with a scalpel to use. The management of the method is that affix drape side of drape gauze on abdominal organ side and put the drape gauze between the abdominal inner layer and abdominal organ, and then place suction drape in the front side of it for air-tight sealing and closure, applying negative pressure of approximately $-125 \mathrm{mmHg}$ (at the time of hemorrhage due to coagulopathy : $-75 \mathrm{mmHg}$ ) [5]. This method enables quick and easy bleeding monitoring. The size of the protective layer sheet to be inserted in the abdominal organ side is enough large to cover all abdominal organs and to reach to the bilateral paracolic gutter. A characteristic thin sponge is contained in this sheet with radial shape (asterisk shape), providing negative pressure to the tip of the sheet (Figure 1A). This enables it to give continuous suction of a place where fluid tends to accumulate in the abdomen. It significantly improved the rate of fascial closure for 30 days and all mortality compared with Barker's method [6]. However, an availability within the insurance only is limited up to 5 times within 10 days.
(A)

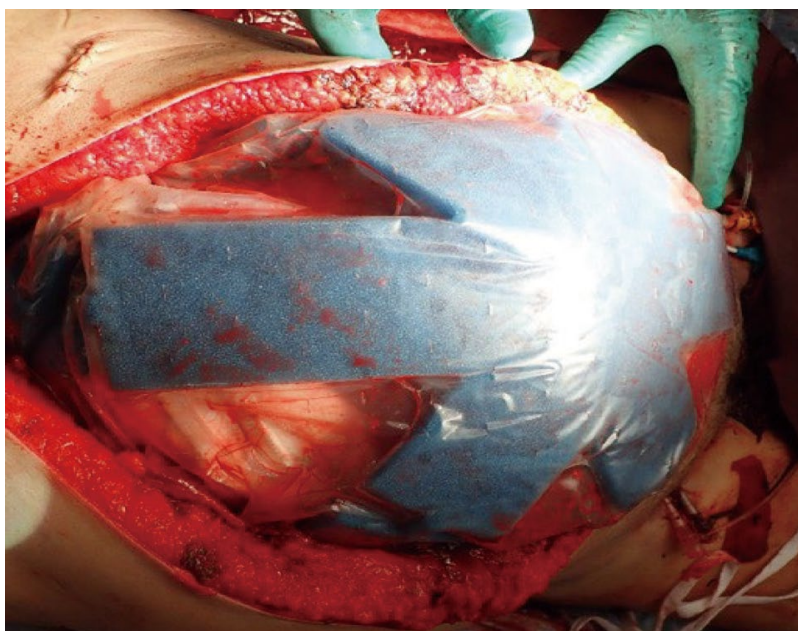

(B)

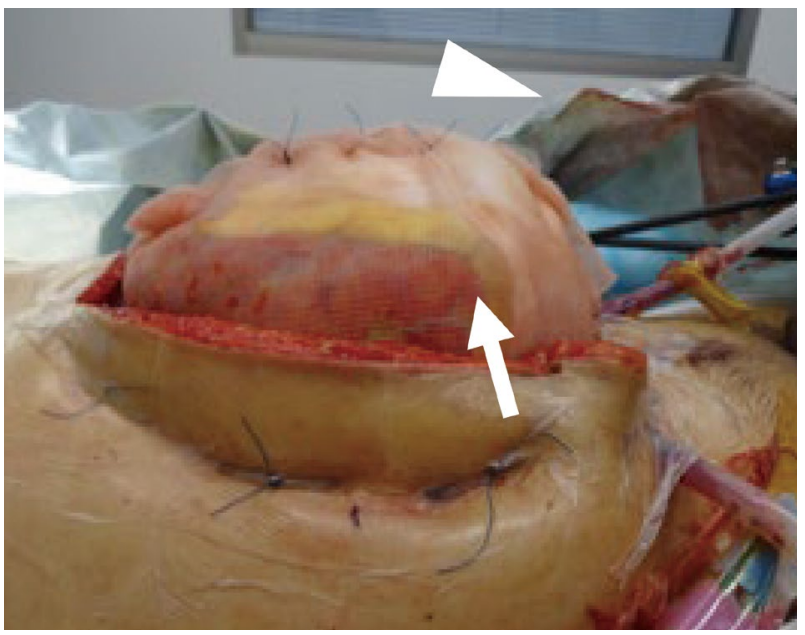

(C)

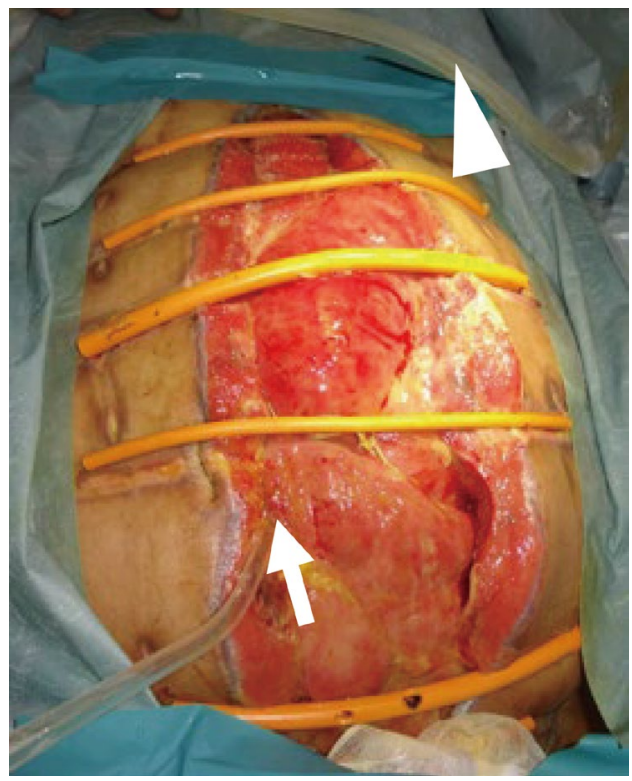

Figure 1 . The abdominal wound appearances.

(A) The protect layer sheet of ABTHERATM was entered into the abdominal cavity.

(B) VPC with mesh mediated fascial traction was performed.

(C) The abdominal wound was developed persistent enteroatmospheric fistula (EAF) during OAM.

White arrow head shows cranial side. White arrow of (B) reveals PROLENE mesh

White arrow of $(C)$ shows EAF.

$\mathrm{EAF}=$ enteroatmospheric fistula; $\mathrm{OAM}=$ open abdomen management; VPC = vacuum packing closure. 


\section{Key Points of OAM for Definitive Abdominal Closure Following DCS}

It is important to stabilize respiratory condition and circulatory state, rewarm body temperature, and improve acidosis and coagulopathy in intensive care following DCS. Abdominal closure methods such as VPC is effective to prevent ACS. However, if there is a massive retroperitoneal hematoma accompanied by severe pelvic fracture, it is necessary to monitor intra-abdominal pressure. Once effective hemostasis is performed and the circulatory state becomes stable, it is important to keep water balance as low as possible for planned reoperation. If it is difficult to close the abdominal wall at the time of planned reoperation, exchange of the VPC system must be executed within 24-72 hours [7]. During this time, appropriate nutritional management is important. Once hemostasis is completed and circulatory state is stabilized and there is no sign of gastrointestinal damage, it is desirable to attempt early enteral feeding [7]. During OAM, since intestinal peristalsis becomes remarkably low and intestinal edema is also observed, it is necessary to administer from small doses of enteral feeding.

When OAM is continued for a long time, fascia retraction may occur. In order to prevent fascia retraction, there are tension closure methods, such as Wittmann Patch method [8] in which tension is steadily applied to the direction of abdominal wall closure, simultaneously attempting VPC, and its fascia closure rate has been reported to be $83 \%$ to $100 \%$ [9]. When a group in which VPC was executed with abdominal tension closure method was compared with VPC without it, it was reported that the group using both methods had significantly higher rate of fascia closure [10]. The VPC with tension closure method is effective in difficult cases of abdominal wall closure. However, Wittmann Patch is available only by personal import in Japan. As an alternative method, there is VPC method executed with the way which sutures non-absorbable mesh on both sides of the abdominal wall and closes rolling it to the direction of approximation of abdomen [10] (Figure 1B), and another VPC method by penetrating wire for sternum closure into all layers of the abdominal wall and gradually tightening it. While performing them, it is necessary to monitor intro-abdominal pressure.

During OAM, caution on complications such as EAF such as EAF must be taken especially. Since intestine which is exposed to the atmosphere is too fragile, EAF is likely to occur in the area (Figure 1C). Even if simple closure is performed for EAF, the perforated spot is spread rather than becoming to be smaller. Therefore, the surrounding area should be gradually granuated and, as a result, transformed it to the stoma. EAF management is very cumbersome and becomes serious sometimes, therefore, it is necessary to proceed with OAM avoiding of EAF.

\section{Various Definitive Abdominal Closure Methods for Difficult Cases of Abdominal Closure Following DCS}

Definitive abdominal closure methods for the difficult cases of abdominal closure following DCS include 1) bilateral anterior rectus abdominis sheath flap turnover method (after exposing the rectus abdominis sheath on both sides, the sheath of the anterior lobe is incised and peeled longitudinally, then inverted medially, and the bilateral sheath is sutured and closed) [11], 2 ) component separation (CS) method ( the innermost portion of the external oblique muscle aponeurosis is incised, and the area between the external and internal oblique muscles is detached and removed from the linea alba, then posterior sheath of the rectus abdominis muscle is detached and closed suturing [12]), 3) abdominal closure method using mesh, 4) planned ventral hernia (PVH) [13] (method of skin-grafting after growing granulation on the intestine and other intraabdominal organs deliberately), 5) thigh musculocutaneous flap method. In addition, there is 6) early planned ventral hernia method (method of early making ventral hernia deliberately with skin-grafting after VPC using absorbable mesh, which we have learned at Chulalongkorn University in Thailand). In case that cannot close the abdomen within 1 week by VPC management following DCS, an absorbable mesh is sutured to the fascia (Figures $2 \mathrm{~A}$ and $2 \mathrm{~B}$ ), and then VPC is performed spreading sterilized polyvinyl chloride and sponge on the mesh (Figure $2 \mathrm{C}$ ). While the mesh is absorbed within about 10 days, granulation occurs and increased during this period (Figure 2D). Skin-grafting can be executed within 10 days to 2 weeks after suturing absorbable mesh. The skin-grafted part is gradually grown up and colonized about 10 days, and the patient can be transferred to another hospital within 1 to 1.5 months. Definitive abdominal wall reconstruction can be performed by delayed CS method about 6 months after discharge. In this method, the increase in intraabdominal pressure is minimal because of the tension-free closure with absorbable mesh. In addition, because abdominal wall reconstruction by fascial detachment is not performed during the acute phase, there is less damage caused by fascial ischemia and infection, therefore the fascia can be used in very good conditions during delayed reconstruction. The negative pressure of the VPC causes the granulation to penetrate into the mesh, and the mesh is absorbed into the granulation while it is integrated, resulting in granulation growth. In case of infection, since the infected part becomes naturally detached, it is unnecessary to remove the entire part, unlike non-absorbable material. Thick granulation is more likely to form than VPC without mesh, which is a good method for the prevention of EAF (Figure 2D). There were no cases of EAF out of 16 trauma cases in which performed this procedure for difficult cases of definitive abdominal wall closure in the last 
(A)

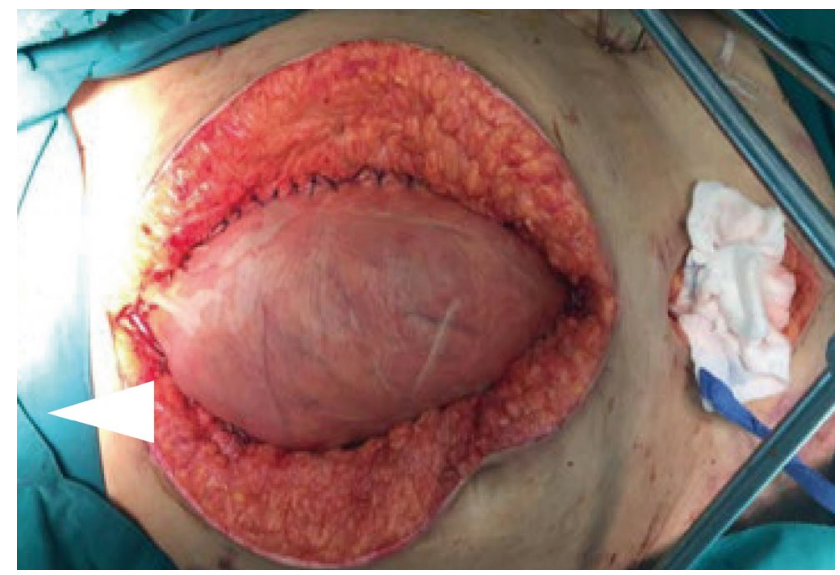

(C)

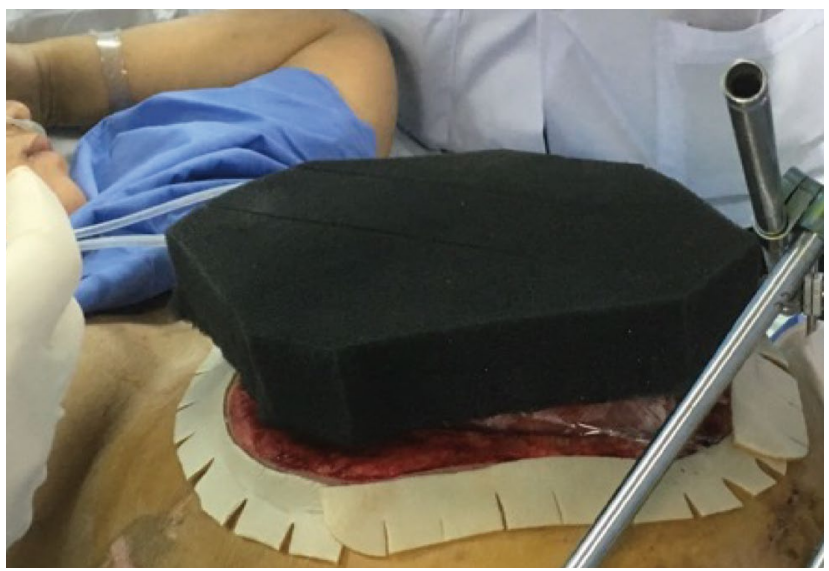

(B)

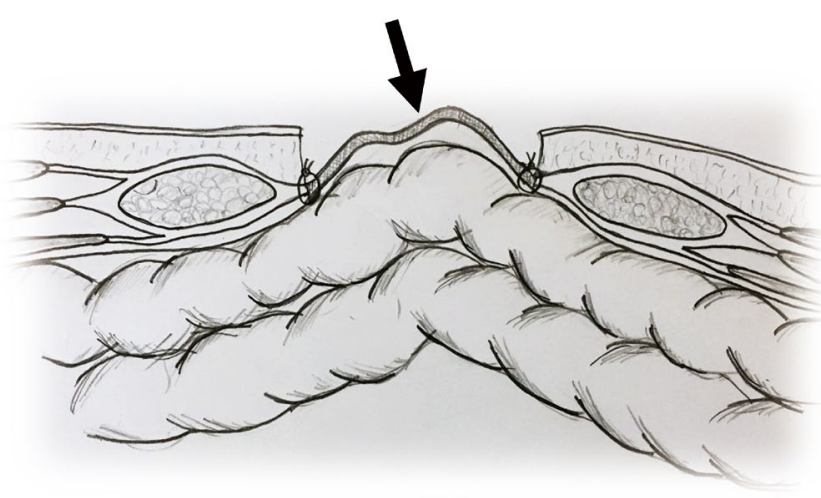

(D)

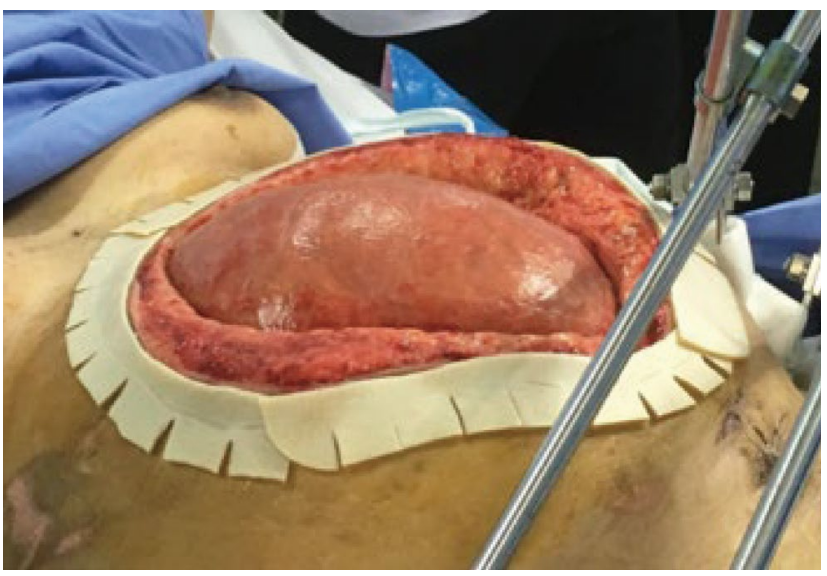

Figure 2. Vacuum packing closure (VPC) using absorbable mesh aiming for planned ventral hernia.

(A) An absorbable mesh was sutured to the abdominal wall to cover up organs to make a planned ventral hernia early on day 7.

(B) Absorbable mesh was interruptedly sutured for fixation to fascia of rectus abdominis muscle and peritoneum.

(C) The layers of VPC were composed of a plastic sheet which put on the absorbable mesh, and sponge which placed on the sheet.

(D) Thick and substantial granulation was formed on organs, assimilating the mesh.

White arrow head shows cranial side. Black arrow reveals an absorbable mesh.

(A)

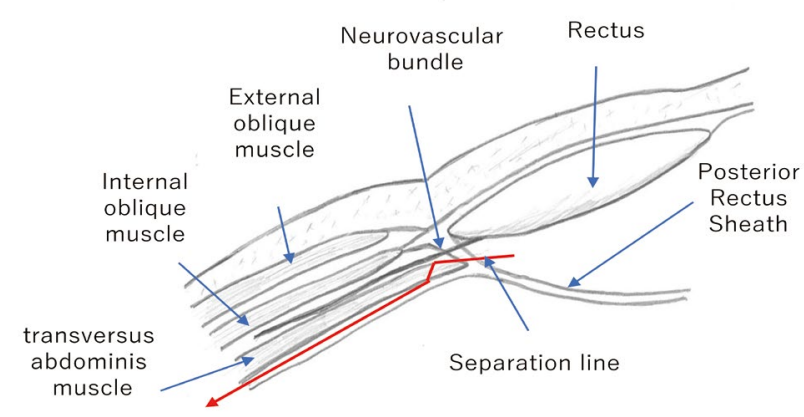

(B)

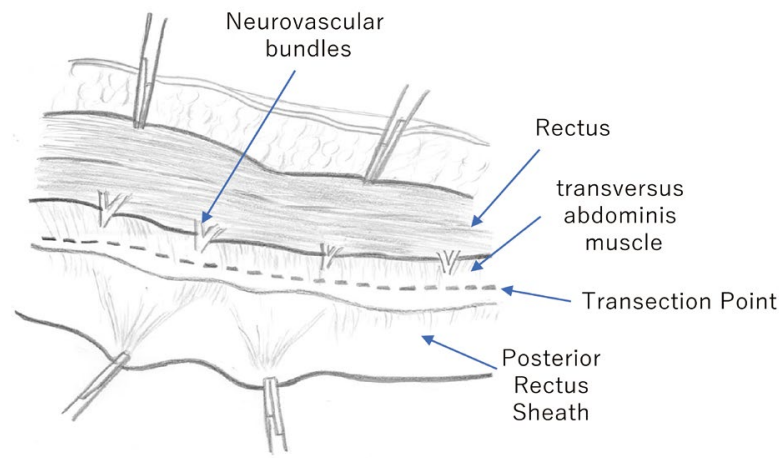

Figure 3. PPosterior component separation/transversus abdominis release (PCS/TAR) method for abdominal reconstruction.

(A) The transversus abdominis muscle can be seen extending medial to the linea semilunaris behind the rectus muscle.

(B) The neurovascular bundles perforating the rectus are seen laterally with the posterior layer dissected off the rectus.

PCS/TAR begins by entering the space between the rectus abdominis muscle and the posterior rectus sheath. The posterior rectus sheath is divided, taking care to avoid the perforating neurovascular bundles. The transversus abdominis muscle is divided. The retromuscular space is then bluntly developed to as far as the lateral border of the psoas muscle. The posterior rectus sheaths are approximated to one another side. 
two years at the same institution.

In addition, 7) posterior component separation with transversus abdominis release (PCS/TAR) method is also considered as a useful abdominal closure method. An abdominal closure is performed detaching the area between the internal oblique muscle aponeurosis and the transversus abdominis muscle at the part of a transition from the posterior lobe of the posterior sheath of the rectus abdominis muscle to the transversus abdominis muscle in the original PCS method [14]. On the other hands, PCS/TAR method is implemented in the way of making an incision on the transverse abdominal muscle at the median side of the neurovascular bundle, preserving the neurovascular bundle to the side of the rectus abdominis muscle at the part of the transition from the posterior lobe of the posterior sheath of the rectus abdominis muscle to the transversus abdominis muscle, peeling away the area between the transverse abdominal muscle and the underlying transverse fascia to the psoas muscle (Figures $3 \mathrm{~A}$ and $3 \mathrm{~B}$ ), and then closing the abdominal wall by securing sufficient membrane tissue to enclose the intra-abdominal organs. It has been reported that a defect with an average maximum lateral diameter of $20 \mathrm{~cm}$ could be closed by PCS/
TAR method [15], and that the PCS/TAR technique has a significantly lower wound complication rate compared with the CS technique because blood flow in the abdominal wall is maintained by preserving the neurovascular bundle without detachment between the subcutaneous tissue and fascia [16]. If the abdomen is unable to be closed by bilateral anterior rectus abdominis sheath flap turnover method and CS method at the delayed abdominal wall reconstruction, PCS/TAR technique can be considered as another option.

\section{Surgical Treatment Guideline in Our Trauma Center for Definitive Abdominal Closure in the OAM Following DCS}

In our trauma center, VPC is the basic method of temporary closure following DCS. Most cases could be closed within one week with this approach. However, over the past 5 years, we have had 5 cases of difficult abdominal wall closure that required long-term OAM after DCS (Table 1 ). We have experienced one case each of abdominal wall reconstruction with CS, PCS/TAR, and anterolateral thigh flap, two cases of

Table 1. Five severe trauma cases which were performed long term OAM after DCS in our center.

\begin{tabular}{|c|c|c|c|c|c|c|c|c|c|c|c|}
\hline $\begin{array}{l}\text { Age/ } \\
\text { sex }\end{array}$ & Mechanism & Injury site & ISS & Ps & TAC & DAC & $\begin{array}{l}\text { Day of } \\
\text { abdominal } \\
\text { closure }\end{array}$ & EAF & Outcome & $\begin{array}{l}\text { Total blood } \\
\text { transfusion } \\
\text { for } 24 \\
\text { hours(unit) }\end{array}$ & $\begin{array}{l}\text { In- out } \\
\text { balance } \\
\text { for } 24 \\
\text { hours } \\
\text { (L) }\end{array}$ \\
\hline $76 / F$ & $\begin{array}{c}\text { Traffic } \\
\text { accident, } \\
\text { walker vs } \\
\text { car }\end{array}$ & $\begin{array}{l}\text { Splenic injury, liver } \\
\text { injury, pelvic fracture, } \\
\text { left multiple rib } \\
\text { fractures, bilateral } \\
\text { pulmonary contusion }\end{array}$ & 57 & 0.058 & VPC & VH & - & - & $\begin{array}{l}\text { Death on } \\
\text { day } 23\end{array}$ & 174 & 23 \\
\hline $\begin{array}{l}37 / \\
M\end{array}$ & $\begin{array}{l}\text { Traffic } \\
\text { accident, } \\
\text { car vs car }\end{array}$ & $\begin{array}{l}\text { Massive mesenteric } \\
\text { injury, pelvic fracture, } \\
\text { left femur fracture, etc }\end{array}$ & 41 & 0.34 & VPC & $\begin{array}{l}\mathrm{VH} \rightarrow \\
\text { anterolateral } \\
\text { thigh flap }\end{array}$ & Day 75 & - & $\begin{array}{l}\text { Discharge } \\
\text { on day } \\
225\end{array}$ & 144 & 16 \\
\hline $\begin{array}{l}78 / \\
M\end{array}$ & $\begin{array}{c}\text { Traffic } \\
\text { accident, } \\
\text { bicycle vs } \\
\text { car }\end{array}$ & $\begin{array}{l}\text { Liver injury, renal } \\
\text { injury, IVC injury, } \\
\text { pulmonary contusion, } \\
\text { multiple rib fractures, } \\
\text { pelvic fracture }\end{array}$ & 57 & 0.12 & $\begin{array}{l}\mathrm{VPC} \rightarrow \\
\text { ABTHERA }^{\mathrm{TM}} \\
\quad \rightarrow \mathrm{VPC}\end{array}$ & CS & Day 33 & - & $\begin{array}{l}\text { Death on } \\
\text { day } 38\end{array}$ & 260 & 29 \\
\hline $\begin{array}{l}43 / \\
M\end{array}$ & $\begin{array}{l}\text { Traffic } \\
\text { accident, } \\
\text { motorcycle } \\
\text { vs car }\end{array}$ & $\begin{array}{l}\text { Massive mesenteric } \\
\text { injury, pelvic fracture, } \\
\text { multiple rib fractures, } \\
\text { hemopneumothorax, } \\
\text { pulmonary contusion, } \\
\text { cerebral contusion, etc }\end{array}$ & 57 & 0.26 & $\begin{array}{l}\mathrm{VPC} \rightarrow \mathrm{VPC} \\
+ \text { mesh } \\
\text { tracion }\end{array}$ & $\begin{array}{c}\mathrm{VH} \rightarrow \\
\text { PCS/TAR }\end{array}$ & Day 465 & + & $\begin{array}{l}\text { Discharge } \\
\text { on day } \\
506\end{array}$ & 150 & 21 \\
\hline $\begin{array}{c}56 / \\
M\end{array}$ & $\begin{array}{c}\text { Traffic } \\
\text { accident, } \\
\text { walker vs } \\
\text { car }\end{array}$ & $\begin{array}{l}\text { Splenic injury, renal } \\
\text { injury, pancreatic } \\
\text { injury, pelvic fracture, } \\
\text { pulmonary contusion, } \\
\text { multiple rib fractures }\end{array}$ & 48 & 0.21 & $\begin{array}{l}\mathrm{VPC} \rightarrow \mathrm{VPC} \\
\quad+\text { wire } \\
\text { traction }\end{array}$ & VH & - & - & $\begin{array}{l}\text { Discharge } \\
\text { on day } \\
215\end{array}$ & 124 & 15 \\
\hline
\end{tabular}

ISS = injury severity score; TRISS PS = Trauma and Injury Severity Score Probability of survival; TAC = temporary abdominal closure; DAC = definitive abdominal closure; DCS = damage control surgery; $\mathrm{EAF}=$ enteroatmospheric fistula; OAM = open abdomen management; VPC = vacuum packing closure; $\mathrm{VH}=$ ventral hernia; $\mathrm{PCS} / \mathrm{TAR}=$ posterior component separation with transversus abdominis release. 
resulting in $\mathrm{VH}$, and one case of EAF during the past 5 years. All cases were associated with severe pelvic fractures, with a total blood transfusion $\geq 100$ units and total fluid balance $\geq 10$ liters within 24 hours.

A variety of treatment guidelines have been reported regarding definitive abdominal closure following DCS [17]. Since there are some devices that cannot be used in Japan, some of those guidelines are unfeasible. It is presented an outline of the surgical guidelines for abdominal wall closure that can be performed in Japan based on our experiences hereby (Figure 4). Temporary abdominal closure is performed with VPC, ABTHERA ${ }^{\mathrm{TM}}$ and etc. after DCS (Phase 1). If it is impossible to close the abdominal wall within about 1 week with these methods, consider adding tension with mesh or wire to them. The aim in Phase 2 is to achieve early definitive abdominal wall closure, using primary fascial closure, bilateral anterior rectus abdominis sheath turnover method, and CS. If the abdomens are unable to be closed, OAM aiming for planned ventral hernia is performed using VPC or wet dressing (Phase 3), and then skin grafting should be performed when granulation has been increased continuing VPC. At this time, it is useful to perform VPC using absorbable mesh for the reduction of the the rate of EAF occurrence. After 6 months to one-year, delayed reconstruction of the abdominal wall should be performed using CS procedure, mesh repair, thigh musculocutaneous flap or PCS/TAR methods according to patients' condition and age (Phase 4). We think that this surgical treatment strategy for abdominal wall closure completely will lead to making a more appropriate decision of abdominal wall closure method.

\section{Conclusion}

In the cases which is unable to close the abdominal wall following DCS, a phase-by-phase approach for definitive abdominal closure should be selected according to various cases. In Japan, VPC/ABTHERA ${ }^{\mathrm{TM}}$ is considered to be the best option as a temporary abdominal closure method during OAM, requiring the application of tension onto fascia for closure according to various cases. However, it is important to recognize that some cases are still difficult to close the abdomen in spite of those methods. In the case that early abdominal closure is not expected and $\mathrm{VH}$ must be performed, it is considered that VPCs using an absorbable mesh reduces the occurrence of EAF and grows granulation earlier and results in being able to perform early skin grafting, contributing to shortening the hospitalization period. As for delayed abdominal wall reconstruction, PCS/TAR method can be an effective option in cases that the CS method and the bilateral anterior rectus abdominis sheath turnover method cannot be performed.

\section{Conflicts of Interest}

The authors have no conflicts of interest to declare.

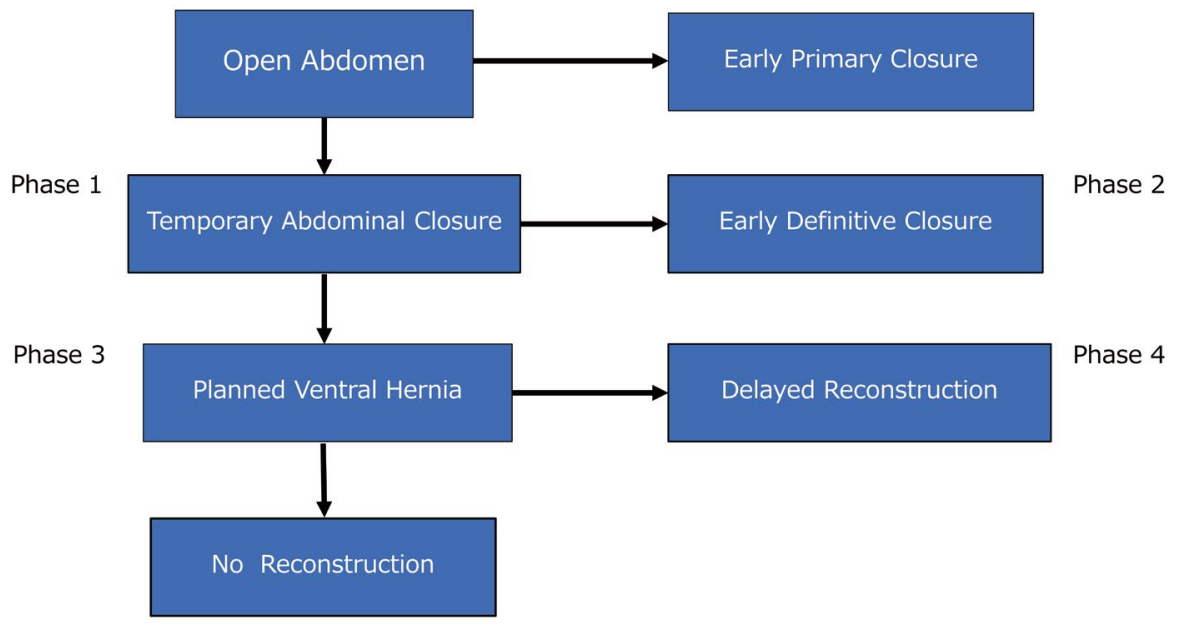

Figure 4. Overview of abdominal closure following DCS which we recommend in our country. Temporary abdominal closure (TAC) such as vacuum packing closure $\left(\right.$ VPC) or vacuum-assisted closure $(V A C) \circledast /$ ABTHERA ${ }^{\text {TM }}$ is performed, which accompanied wire traction or meshmediated fascial traction occasionally in Phase 1. Early definitive closure is undergone using acute component separation or bilateral anterior rectus abdominis sheath turnover method etc. after TAC. If the abdomens are unable to be closed, OAM aiming for planned ventral hernia is performed using VPC or wet dressing (Phase 3 ) and the delayed reconstruction of the abdominal wall is occasionally performed according to patients' condition (Phase 4). 


\section{References}

[1] Roberts DJ, Bobrovitz N, Zygun DA, Ball CG, Kirkpatrick AW, Faris PD, et al. Indications for Use of Damage Control Surgery in Civilian Trauma Patients: A Content Analysis and Expert Appropriateness Rating Study. Ann Surg 2016;263(5):1018-27.

[2] Bradley M, Galvagno S, Dhanda A, Rodriguez C, Lauerman M, DuBose J, et al. Damage control resuscitation protocol and the management of open abdomens in trauma patients. Am Surg 2014;80(8):768-75.

[3] Offiner PJ, de Souza AL, Moore EE, Biffl WL, Franciose RJ, Johnson JL, et al. Avoidance of abdominal compartment syndrome in damage-control laparotomy after trauma. Arch Surg 2001;136(6):676-81.

[4] Barker DE, Kaufman HJ, Smith LA, Ciraulo DL, Richart CL, Burns RP. Vacuum pack technique of temporary abdominal closure: a 7-year experience with 112 patients. J Trauma 2000;48(2):201-6.

[5] BChiara O, Cimbanassi S, Biffl W, Leppaniemi A, Henry S, Scalea TM, Catena F, et al. International consensus conference on open abdomen in trauma. J Trauma Acute Care Surg 2016;80(1):173-83.

[6] Cheatham ML, Demetriades D, Fabian TC, Kaplan MJ, Miles WS, Schreiber MA, et al. Prospective study examining clinical outcomes associated with a negative pressure wound therapy system and Barker's vacuum packing technique. World J Surg 2013;37(9):2018-30.

[7] McClave SA, Taylor BE, Martindale RG, Warren MM, Johnson DR, Braunschweig C, et al. Guidelines for the Provision and Assessment of Nutrition Support Therapy in the Adult Critically Ill Patient: Society of Critical Care Medicine (SCCM) and American Society for Parenteral and Enteral Nutrition (A.S.P.E.N.). JPEN J Parenter Enteral Nutr 2016;40(2):159211.

[8] Fantus RJ, Mellett MM, Kirby JP. Use of controlled fascial tension and an adhesion preventing barrier to achieve delayed primary fascial closure in patients managed with an open abdomen. Am J Surg 2006;192(2):243-7.

[9] Cheesborough JE, Park E, Souza JM, Dumanian GA. Staged management of the open abdomen and enteroatmospheric fistulae using split-thickness skin grafts. Am J Surg 2014;207(4):504-11.

[10] Salamone G, Licari L, Guercio G, Comelli A, Mangiapane M, Falco N, et al. Vacuum-Assisted Wound Closure with Mesh-Mediated Fascial Traction Achieves Better Outcomes than Vacuum-Assisted Wound Closure Alone: A Comparative Study. World J Surg 2018;42(6):1679-86.

[11] Kushimoto S, Aiboshi J, Arai M, Harada N, Isobs M, Tanabe S, et al. Usefulness of the Bilateral Anterior Rectus Abdominis sheath Turnover Flap Method for Early Fascial and Wound Closure in Patients Requiring Open Abdomen. Jpn Soc Abdom Emerg Med 2007;27(1):27-35.

[12] Ramirez OM, Ruas E, Dellon AL. "Components separation" method for closure of abdominal-wall defects: an anatomic and clinical study. Plast Reconstr Surg 1990;86(3):519-26.

[13] Jernigan TW, Fabian TC, Croce MA, Moore N, Pritchard FE, Minard G, et al. Staged management of giant abdominal wall defects: acute and longterm results. Ann Surg 2003;238(3):349-55; discussion 355-7.

[14] Wantz GE. Giant prosthetic reinforcement of the visceral sac. Surg Gynecol Obstet 1989;169(5):408-17.

[15] Jones CM, Winder JS, Potochny JD, Pauli EM. Posterior Component Separation with Transversus Abdominis Release: Technique, Utility, and Outcomes in Complex Abdominal Wall Reconstruction. Plast Reconstr Surg 2016;137(2):636-46.

[16] Krpata DM, Blatnik JA, Novitsky YW, Rosen MJ. Posterior and open anterior components separations: a comparative analysis. Am J Surg 2012;203(3):318-22; discussion 322.

[17] Sharrock AE, Barker T, Yuen HM, Rickard R, Tai N. Management and closure of the open abdomen after damage control laparotomy for trauma. A systematic review and meta-analysis. Injury 2016;47(2):296306. 